\title{
Kernos
}

Revue internationale et pluridisciplinaire de religion grecque antique

5| 1992

Varia

\section{Pierre HADOT, Plotin. Traité 50 (III, 5). Introduction, traduction, commentaire et notes}

\author{
Vinciane Pirenne-Delforge
}

\section{OpenEdition \\ Journals}

\section{Édition électronique}

URL : http://journals.openedition.org/kernos/1078

DOI : 10.4000/kernos. 1078

ISSN : 2034-7871

\section{Éditeur}

Centre international d'étude de la religion grecque antique

\section{Édition imprimée}

Date de publication : 1 janvier 1992

ISSN : 0776-3824

\section{Référence électronique}

Vinciane Pirenne-Delforge, « Pierre нADOт, Plotin. Traité 50 (III, 5). Introduction, traduction, commentaire et notes », Kernos [En ligne], 5 | 1992, mis en ligne le 20 avril 2011, consulté le 24 septembre 2020. URL : http://journals.openedition.org/kernos/1078 ; DOI : https://doi.org/10.4000/kernos.1078 
l'attaque de Sextus Empiricus contre la théologie dogmatique, et traite avec beaucoup de finesse des problèmes concernant la pensée théologique de Plotin.

Le livre comporte une bibliographie (p. 311-324), un index général (p. 325-332), ainsi qu'un index des textes cités (p. 333-340).

Éveline LOUCAS-DURIE (Athènes)

Pierre HADOT, Plotin. Traité 50 (III, 5). Introduction, traduction, commentaire et notes, Paris, Éd. du Cerf, 1990, 1 vol. 12,5 x 19,5 cm, 291 p. (Coll. Les écrits de Plotin publiés dans l'ordre chronologique sous la direction de Pierre Hadot). ISBN : 2-204-04135-1. Prix : 140 FF.

Cet ouvrage est le deuxième d'une collection qui s'attache à fournir au public une traduction des œuvres de Plotin (cf. Kernos, 1 [1988], p. 253, pour le compte rendu du premier volume). Le traité 50 du philosophe pose la question de savoir si l'Amour - Éros - est un Dieu, un démon ou un état de l'âme. Partant des mythes du Banquet de Platon concernant les deux Aphrodites et la naissance d'Éros, de même que de considérations du Phèdre, Plotin propose un exercice d'exégèse allégorique qui lui permet «d'amener l'âme à découvrir que ce qui fait naître en elle l'Amour, c'est à la fois la présence et l'absence du bien en elle» (p. 21).

Pour l'historien de la religion grecque, cette œuvre est une illustration intéressante de l'utilisation de mythes parmi les plus anciens et les plus connus des Grecs par une pensée philosophique qui y décèle un certain nombre de réalités métaphysiques qu'il s'agit de traduire. Dans le cas présent du thème de la double Aphrodite, "ouranienne» et "pandémienne», P. Hadot a également montré, dans un bref appendice, l'influence du traité 50 de Plotin sur la pensée et l'art de la Renaissance. Ainsi voit-on Botticelli et le Titien, puisant aux sources antiques par l'intermédiaire de Marsile Ficin et de Pic de la Mirandole, offrir l'image d'une "Vénus" dont la conception se trouve davantage chez Plotin que dans la Théogonie hésiodique.

Soulignons enfin que ce petit ouvrage est remarquablement écrit et que la traduction élégante du traité en rend l'abord très agréable.

\section{Vinciane PIRENNE-DELFORGE (Liège)}

Greg R. STANTON, Athenian Politics c. 800-500 B.C. A Source Book, London-New York, Routledge, 1990, 1 vol. 13,5 x 21,5 cm, 226 p.

Le développement politique et l'évolution sociale de la démocratie athénienne pendant la période archaïque sont le sujet de cet ouvrage. L'«Attique d'avant Solon», «Solon», «De Solon à Pisistrate», «la tyran- 